\title{
Development Model for Android-based Shot Put Orthodox Styles
}

\author{
Ucok Hasian Refiater*, James Tangkudung, Hernawan \\ Postgraduate Program, Physical Education Study Program (S3), Jakarta State University, Jakarta, Indonesia
}

Received September 22, 2020; Revised November 27, 2020; Accepted December 22, 2020

\begin{abstract}
Cite This Paper in the following Citation Styles
(a) : [1] Ucok Hasian Refiater, James Tangkudung, Hernawan, "Development Model for Android-based Shot Put Orthodox Styles, "International Journal of Human Movement and Sports Sciences, Vol. 8, No. 6A, pp. 51-56, 2020. DOI: 10.13189/saj.2020.080709.
\end{abstract}

(b) : Ucok Hasian Refiater, James Tangkudung, Hernawan (2020). Development Model for Android-based Shot Put Orthodox Styles. International Journal of Human Movement and Sports Sciences, 8(6A), 51-56. DOI: 10.13189/saj.2020.080709.

Copyright $\bigcirc 2020$ by authors, all rights reserved. Authors agree that this article remains permanently open access under the terms of the Creative Commons Attribution License 4.0 International License

\begin{abstract}
This study aims to develop an Android-based model of measurement in orthodox shot put styles. The research method used is research and development which adapted from Borg and Gall's theory including the 10 stages of development. The research subjects were 12 males and females athletes. Data collection uses observation, questionnaire, interview, and test. Data analysis technique used in this research is descriptive qualitative and statistics analysis. The result showed the average value of the small-scale trials with 8 subjects of athletic athletes is $82 \%$ in the category "Good" which means the android-based shot put gauge is "feasible" to be used as an orthodox shot put style. The average value of large-scale group trial with 12 subjects of athletic athletes is $86,2 \%$ also in category "Good" meaning the Android- based shot put is also "feasible" to be used as a gauge for orthodox shot put style. The conclusion from this study is the Android-based in orthodox shot put measurement test instrument which is feasible to be applied to measure the results of shot put. Future research can develop further in sensor system. However, the sensors used in UDM devices use laser sensors.
\end{abstract}

Keywords Measurement Model, Shot Put, Resistant, Orthodox, Android

\section{Introduction}

Along with the development of sports science, the field of sports has drastically changed to become more technical that challenging scientists and coaches in applying their knowledge with the constant technological development. The terminology regarding technological objects to facilitate or enhance sports is not consistent. The terms of "sports technology" is used as a synonym for technical objects used for sports. Different from what commonly used terms as "sports equipment", the concept of sports technology encompasses various objects which have a technology base [1]. Technology is philosophically defined as a physical instrument that can be used for problem-solving [2]. A number of studies on technology in sports have previously been used such as: systematic reviews of global positioning systems (GPS) and micro sensor technology in team sports [3], reviews based on motion analysis in sports [4], video usage in training [5], integrated technologies such as GPS, accelerometers and heart rate monitors in team sports [6].

Recently, sports technology can be seen as part of the athlete's needs, enabling the integration of humans and objects, also enabling the emergence of recent discoveries through more specific analysis [7]. An interesting example of technological development taking place in sports through the application of innovative technology taken from other disciplines is the use of drones (unmanned camera sets) [8]. These advances have made it possible for researchers and applied sports scientists to easily measure key aspects of performance in the field, which previously often could be done in a laboratory only. [9]. In addition to technology, athlete performance is also supported by good and tiered training. 
Athletes must be trained perfectly to get the best result in their performance. This is reinforced by the opinion of James Tangkudung [10] that "achievement can only be achieved if coaching can be worked and focused on aspects of training that fully included: athlete's personality, physical condition, technical measurement, tactical measurement and mental ability, these five aspects constitute a unified whole. .'Paralysis with analysis' is a general result that results from conscious control of a movement that is usually automatic, which is very likely caused by information overload and ongoing monitoring [11]. Therefore, a large number of studies have analyzed measurably differences in performance from year to year on throwing numbers in athletic sporting branches [12].

One of the most prominent advances in the field of data collection and processing methods is the computer analysis system. Computer vision uses algorithms to detect identification features in video clips such as patterns or color differences [13]. A computer analysis system requires several cameras to be placed around a sports area, and can require manual input as a calibration of the game event [14]. Meanwhile, developments in the use of computer analysis technology to automate the capture of player movements continue with evaluations developed [15]. Evaluation is done by measuring students' physical fitness tests [16]. For example, accurate player tracking data collection can be a problem when several players are collected in a small area [17]. Slow-motion technology using computers also plays a role in the development of motion analysis in biomechanics and other sports sub-disciplines, with products such as Microsoft KinectTM being used as a low-cost solution for analyzing motion [18]

The increasing distance from the throwing performance of athletes makes athletes in the athletics throwing branch realize that a more accurate and uniform device is needed to measure the distance from the throw. Finally, the development of distance measurement technology has developed rapidly. One technology that continues to develop in distance measuring devices in athletics is the Electronic measurement device (EDM). Electronic Distance Measurement (EDM), used in eight events in athletics: high jump, long jump, triple jump, pole jump, discus throwing, shot put, hammer throw, and javelin throwing. EDM tools during its development have been through many improvements to become a tool that has high precision as it is now [19].

The problem that currently exists in athletics, especially the number of throwing, is that there are still very few EDM tools owned by the PASI organization at the provincial or district/city level in Indonesia. This certainly can affect the implementation of an athlete's training results especially when they want to take the shot put because if using a manual test it will affect the results obtained are not accurate. Also, when a race event does not use accurate and digital measuring instruments, it can cause chaos because the results using manual measuring tools are not accurate.

Based on these problems, it is necessary to research the development of measuring devices with the aim that the resulting product will provide an easy and effective solution used to measure shot put skills. According to Seels and Richey in Ardani, development can be interpreted as a process of translating or describing design specifications into physical features. Tessmer and Richey state that development focuses not only on needs analysis but also on broad issues about initial analysis, such as contextual analysis [20]. The development of volleyball learning model produces product models learning [21]. The results of his research are the development of scoring applications in soccer games [22]. The results of his research on the development of service-learning are products for volleyball [23]. The results of his research are computer-based volleyball skills test instrument products [24].

Based on these problems, the researchers wanted to develop orthodox style shot put measuring devices based on Android. After this measuring device has been made and has been tested for the feasibility of the tool, it is expected that the shot put gauge can be a solution to make it easier for athletes, coaches and sports teachers to evaluate the results of orthodox style. The Orthodox style is also called a sideways style. The meaning of in shot put is a technique of putting a bullet that is performed sideways to produce repulsion as far as possible using the strength of the arms, legs, feet thighs and hips. Orthodox is one of styles in shot put. It is usually used by athletes in competition because is still relatively easy compared to other styles.

\section{Research Method}

The research approach used in this study is research and development, chosen based on the suitability of the objectives to be achieved in the form of a development model for Android-based shot put distance measurement tool or system.

\subsection{Place of Research}

The study was conducted at the East Jakarta Rawamangun Athletic Stadium.

\section{Refresh Subject}

The subjects of this study consist of 12 shot put athletes from Sports Faculty State University of Jakarta. In details, there are 8 male athletes and 4 female athletes in the range of 17-20 years old. In general, they have large and tall posture and relatively big strong muscles. 


\subsection{Data Collection Technique}

Data collection techniques in this study; (1) Field observation where the research subjects were being analyzed, and (2) Interviews, direct communication with athlete trainers.

\section{1) Observation}

The observation was held to find out and observe the situation and its conditions regarding the instrument used and other supporting facilities at the research site. Researchers participate directly as a process of observing according to the circumstances in the field.

\section{2) Interview}

Interviews were conducted with the trainers.

\subsection{Data Collection Instruments}

The instrument in this research development is to use several data collection methods. Sugiyono stated [25] the questionnaire is a data collection technique by giving written questions to respondents. Questionnaire can be in a closed/ open question/ statement. According to Sugiyono the types of questionnaires are divided into three; (1) Multiple choice questionnaire, (2) Checklist. (3) Rating scale [25].

\subsection{Data Analysis Technique}

Data analysis includes all the activities of clarifying, analyzing, using, and drawing conclusions from all data collected in action. Whereas quantitative data were obtained by giving a score on a qualitative based on a Likert scale that was converted to a scale value of 4 . The Percentage is intended to find out the status of something that is presented through a percentage. The formula for calculating eligibility according to Sugiyono is as follows. The results of subsequent data calculations are made in the form of a percentage multiplied by $100 \%$ and in the four categories of eligibility by using the Scale as include [25]. Percentage of Eligibility Category by Arikun [25].

Note: (1): Strongly disagree / very improper, (2): Not appropriate / not feasible, (3): Appropriate / feasible, (4): Very appropriate / very feasible.

\section{Results and Discussion}

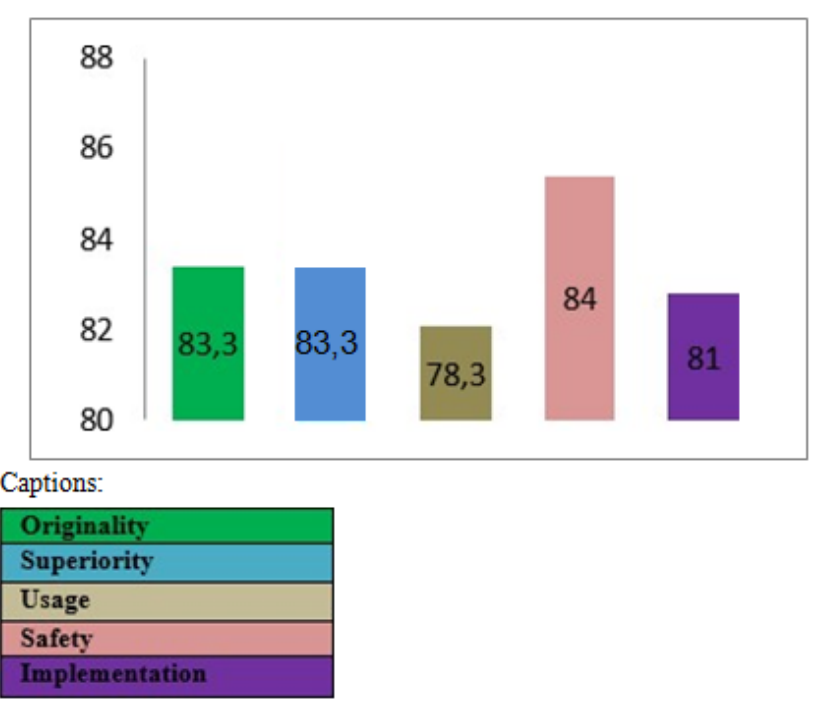

Figure 1. Diagram of Small Scale Trial Results

Based on the diagram figure 1 above, the results of large-scale group trials in the aspect of originality the android-based shot put gauge obtained $83.3 \%$ in the "Good" category. It means that the android-based shot put gauge is "feasible" to proceed to the stage of tool implementation. The superiority aspect of android-based shot put measuring devices gaining $83.3 \%$ in the "Good" category that show digital-based athletic measurement test kits are "feasible" to proceed to the stage of tool implementation. The aspect of the use of android-based shot put measuring instruments obtains a score of $78,3 \%$ in the category of "Good". It also means that the androidbased shot put gauge is "feasible" to proceed to the stage of tool implementation. The safety aspect of the androidbased shot put measuring device scores $84 \%$ in the "Good" category, showing that the android-based shot put gauge is "feasible" to proceed to the stage of tool implementation. The aspect of using android-based shot put measuring devices has a value of $81 \%$ in the category of "Good" meaning that the android-based shotgun gauge is "feasible" to proceed to the stage of tool implementation. So the average value of the results of large-scale group trials is $81,98 \%$ in the category of "Good" which means that the android-based shot put gauge is "feasible" to proceed to the stage of tool implementation. 


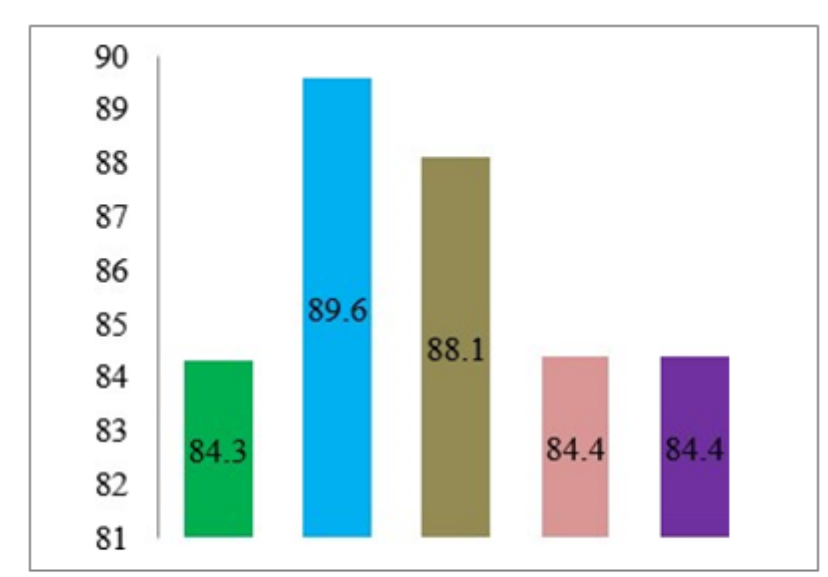

Captions:

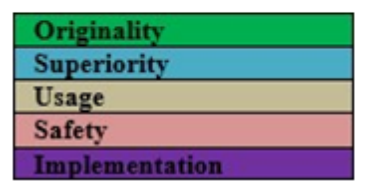

Figure 2. Diagram of Small Large Scale Trial Results

Based on the diagram figure 2 above, the results of a small trial in the diagram in the aspect of originality the android-based shot put gauge has an $84.3 \%$ score in the "Good" category meaning that the android-based shot put gauge is "feasible" to proceed to the large-scale trial phase after being corrected accordingly with the advice given. The great aspect of the android-based shot put measuring device scores $89.6 \%$ in the category of "Good" which means that the digital-based athletic measurement measuring instrument is "feasible" to proceed to the largescale trial phase after being corrected in accordance with the advice given. The aspect of the use of android-based shot put gauges with a score of $88.1 \%$ in the category of "Good" means that android-based shot put gauges are also "feasible" to proceed to the large-scale trial phase after being corrected in accordance with the advice given. The safety aspect of android-based shot put gauges is $84.4 \%$ in the "Good" category, meaning that android-based shotgun gauges are "feasible" to proceed to a large-scale trial after being corrected according to the advice given. The aspect of using an android-based shot put gauge has an $84.4 \%$ score in the "Good" category meaning that an androidbased shot put gauge is "feasible" to proceed to a largescale trial phase after being corrected as the advice given. So the average value of the results of small-scale trials is $86.2 \%$ in the category of "Good" which means that the android-based shot put gauge is "feasible" to proceed to the large-scale trial phase after being repaired.

\section{Discussion}

This development research is based on the needs of the members of the PASI organization who currently do not have an Android-based throwing number measurement tool yet. So, with the existence of this development product, this can be used by all people and organizations of PASI. This tool is named Ucok Distance Measuring (UDM). Development research conducted by Insook Kim and Bomna Ko conclude that, in the world of education there is also a need for development between K-12. Thus, development research is very effective to be used as a research method[29].

The Android-based Orthodox style shot put gauge products are as follows:

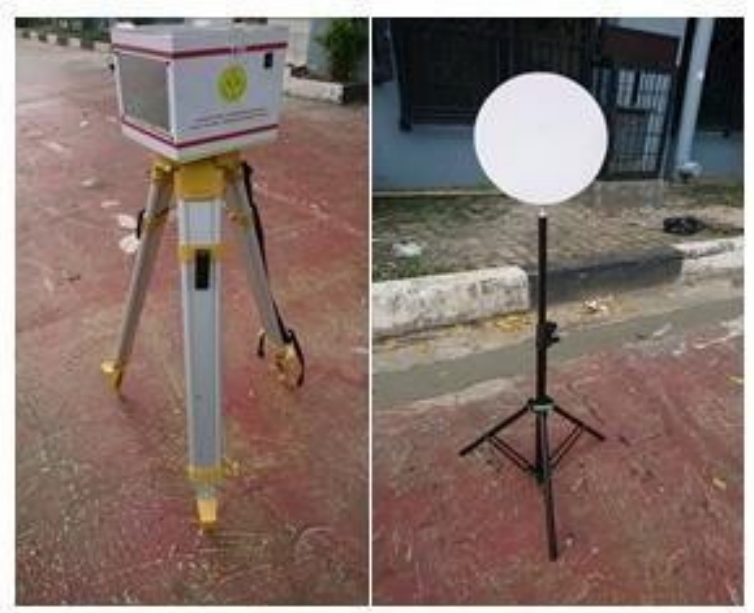

\section{Novelty}

The novelty of this development research includes various aspects, in terms of technology used, the function of the tool, and the shape of the measuring instrument which certainly has a difference with the previous measuring devices.

\section{1) Novelty of Technology}

Table 1. Compare the Types of Technology Used in Manufacturing Tools

\begin{tabular}{|c|c|}
\hline $\begin{array}{c}\text { Alge Distance Measuring } \\
\text { Devices (ADMD) (Theodolites) }\end{array}$ & $\begin{array}{c}\text { Ucok Distance Measuring } \\
\text { (UDM) }\end{array}$ \\
\hline Tripod & Tripod \\
\hline Target & Microprocessor \\
\hline Prismastic Reflector & Penahan Laser \\
\hline Serial Cable & Laser \\
\hline Null Modem/gender Changer & $\begin{array}{c}\text { Scrup Penyambung Laser } \\
\text { dan Penahan }\end{array}$ \\
\hline Sighting Unit & Tombol pengukur \\
\hline Battery Charger & Dudukan Peyambung Tripod \\
\hline Battery & Led Android 14" \\
\hline
\end{tabular}

Based on a detailed table 1 of the technology components used in making each measure above, there are many different types of components used. In terms of the price per unit component, of course, the UDM shot put gauge components are cheaper and easier to obtain. Then the most prominent thing is, UDM has used Android 14 
"LED technology as a supporting component in the operation of tools that have been connected with the Android smartphone application.

\section{Novelty of Usage}

Android-based UDM shot put gauge is quite easy to understand by its usage. The applications are accessible through the smart phone or android application so the users can use and know the results in any circumstances without coming to the exact location. The procedure is not complicated as after conducting the test. The data will be stored in the application automatically, making it easier for users to access the document results of the tests performed. The results also can be directly ranked, so the determination of the champions can be immediately known unlike in Alge system as the calculation is manual and takes a long time, errors often happen as human errors is normal and inevitable which can harm the athletes.

Thus, in UDM system, the track record of each athlete will be stored properly, so it will be more objective and trustworthy. The trainer will also simply evaluate and make reference data when compiling an exercise program. Particularly for the umpire and judges of the shot put, a transparent judging process as the data of the results can be known by the audience, coaches, athletes, and other media through the existing monitor display.

\section{Conclusions}

Based on several stages of validity test and expert validity, the calculation of small-scale group trials and large-scale group trials obtained an average. The result of the small-scale trial average value is $82 \%$ in the "Good" category, which means the Android-based shot put measuring instrument is "feasible". Furthermore, the average value of the large-scale group trials is $86.2 \%$ in the "Good" category, which means the Android-based shot put measuring instrument was "feasible" for measuring the Orthodox style. Android-based in orthodox shot put measurement test instrument is feasible and recommendable to be applied to measure the results of shot put. Future research can develop further in sensor system however the sensors used in UDM devices use laser sensors.

\section{REFERENCES}

[1] Ebert, Christoph B. H. 2010. "Description and evaluation of the functionality of sports products." Technische universität münchen.

[2] Soltanzadeh, Sadjad. 2014. "Humanist and Nonhumanist Aspects of Technologies as Problem Solving Physical Instruments." Philosophy and Technology.
[3] Cummins, Cloe, Rhonda Orr, Helen O'Connor, and Cameron West 2013. "Global Positioning System (GPS) and Microtechnology sensors in Team Sports: A Systematic Review." Sports Medicine 43(10):1025-42.

[4] Barris, Sian, and Chris Button. 2008. "A Review of Vision-Based Motion Analysis in Sport." Sports Medicine 38(12):1025-43.

[5] Choppin, Simon, and Jonathan Wheat. 2013. "The Potential of the Microsoft Kinect in Sports Analysis and Biomechanics." Sports Technology 6(2):78-85.

[6] Dellaserra L., Carla, Yong Gao, and Lynda Ransdell. 2014. "USE OF Integrated Technology In Team Sports: A review Of Opportunities, Challenges, And Future Directions For Athletes." Journal of Strength and Conditioning Research 28(2):556-73.

[7] Gebauer, Gunter, Thomas Alkemeyer, Uwe Flick, Bernhard Boschert, and Robert Schmidt. 2004. Fidelity to Style: The Listed Society (X-Texts on Culture and Society). bielefeld.

[8] Natalizio, Enrico, Rosario Surace, Valeria Loscri, Francesca Guerriero, and Tommaso Melodia. 2013. "Two Families of Algorithms to Film Sport Events with Flying Robots." Proceedings - IEEE 10th International Conference on Mobile Ad-Hoc and Sensor Systems, MASS 2013 319-23.

[9] Giblin, Georgia, Elaine Tor, and Lucy Parrington. 2016. "The Impact of Technology on Elite Sports Performance." Sensoria: A Journal of Mind, Brain \& Culture 12(2):2-9.

[10] Tangkudung, James. Wahyuningtyas Puspitorini. (2012). Sports Coaching. Jakarta: Cerdas Jaya.

[11] Ehrlenspiel, Felix. 2001. "Paralysis by Analysis? A Functional Framework for the Effects of Attentional Focus on the Control of Motor Skills." European Journal of Sport Science 1(5).

[12] Frossard, Laurent, James Smeathers, Alison O'Riordan, and Scott Goodman. 2007. "Shot Trajectory Parameters in Gold Medal Stationary Shot-Putters during World-Class Competition." Adapted Physical Activity Quarterly 24(4):317-31.

[13] Perš, Janez, and Stanislav Kovačič. 2000. "Computer Vision System for Tracking Players in Sports Games." International Symposium on Image and Signal Processing and Analysis, ISPA 177-82.

[14] Sa, Inkyu, and Ho Seok Ahn. 2015. "Visual 3D ModelBased Tracking toward Autonomous Live Sports Broadcasting Using a VTOL Unmanned Aerial Vehicle in GPS-Impaired Environments." International Journal of Computer Applications 122(7):1-7.

[15] Wilson, Barry D. 2008. "Development in Video Technology for Coachingy." Sports Technology 1(1):34-40.

[16] Muslimin, Muslimin, and Arif Hidayat. 2017. "Evaluation of the 2016 South Sumatra Sriwijaya State Sports School Soccer Team

[17] Moeslund, Thomas B., Graham Thomas, and Adrian Hilton. 2014. Advances in Computer Vision and Pattern Recognition. Switzerland: Springer.

[18] Barros, Ricardo M. L., Milton S. Misuta, Rafael P. Menezes, Pascual J. Figueroa, Felipe A. Moura, Sergio A. Cunha, 
Ricardo Anido, and Neucimar J. Leite. 2007. "Analysis of the Distances Covered by First Division Brazilian Soccer.

[19] Rüeger, J. M. 2012. "Recent Developments in Electronic Distance Measurement." Australian Surveyor 30(3):17077.

[20] Ardani, Muryanti. 2015. "Pengembangan Multimedia Bentuk Video Compact Disc (VCD) Dalam Pelatihan Teknik Dasar Aerobic Gymnastic Untuk Anak Usia Dini." Universits Negeri Yogyakarta.

[21] Destriani, Destriani, Destriana Destriana, Endang Switri, and Herri Yusfi. 2019. "The Development of Volleyball Games Learning for Students." Jurnal SPORTIF : Jurnal Penelitian Pembelajaran 5(1):16.

[22] Hartati, H., A. R. Victorian, S. Aryanti, D. Destriana, andD. Destriani. 2018. "Application of Model Development of
Soccer Physical Tests." in IOP Conference Series: Materials Science and Engineering. Vol. 434.

[23] Destriana, Endang Switri, and Herri Yusfi. 2020. "Development of Overhand Serves Learning Techniques in Volleyball Game."

[24] Arif. H. Muslimin. 2018. "Development of test devices and measurement of computer-based volleyball passing. " Development of a computer-based volleyball passing test and measurement device 17(2):297-304.

[25] Sugiyono. (2010). Metode Research Methods Quantitative, Qualitative, and R\&D Approaches. Bandung: ALFABETA

[26] Kim and Bomna Ko, (20016). Developing Elementary Content Knowledge in Physical Education Teacher Education. International Journal of Human Movement and Sports Sciences 4(2): 13-19, 2016 http://www.hrpub.org DOI: $10.13189 /$ saj.2016.040201 